\title{
DILMA ROUSSEFF: AS ELEIÇÕES E A LÓGICA ANDROCÊNTRICA NA POLÍTICA BRASILEIRA
}

\author{
Amanda Motta Castro ${ }^{1}$ \\ Marcio Caetano ${ }^{2}$
}

\begin{abstract}
RESUMO: Com este artigo nos propomos a analisar os modos como as dinâmicas androcêntricas desestabilizam e deslegitimam a presença da mulher no cenário político brasileiro. Para tanto, balizamos nossa análise na emergência eleitoral da candidatura de Dilma Rousseff à presidência da república em 2010. Ao nos centrarmos no percurso eleitoral de Dilma Rousseff, observamos como o trânsito e as participações mantidas pelos diferentes sujeitos na política brasileira assumem configurações diversas, buscando interditar os conhecimentos da mulher e as diferentes formas de entender os espaços e as práticas políticas, afiançando o androcentrismo e a heteronormatividade.
\end{abstract}

Palavras-chaves: Eleição; Dilma Rousseff; Assimetria sexual.

\section{DILMA ROUSSEFF: ELECTIONS AND ANDROCENTRIC LOGIC IN BRAZILIAN POLITIC}

\begin{abstract}
In this paper, our proposal is to analyze the means how androcentric dynamics destabilize and delegitimize the women presence in the Brazilian political scene. To that end, we focused our analysis on the electoral emergence of Dilma Rousseff's candidacy for the Presidency of the republic, in 2010. When we focus on Dilma Rousseff's electoral trajectory, we observe how the traffic and the participations, supported by different subjects in Brazilian politics, assume different configurations, trying to interdict women knowledge and the different ways of understanding political spaces and practices, guaranteeing the androcentrism and heteronormativity.
\end{abstract}

Keywords: Political election; Dilma Rousseff; Sexual asymmetry.

\section{INTRODUÇÃO}

Memória e esquecimento são, assim, indissociáveis na enunciação do político. (COURTINE, 1999: 22).

Uma vez que as assimetrias sexuais afetam as formas como historicamente os coletivos de pessoas têm estabelecido relações dentro dos sistemas democráticos, propomo-

\footnotetext{
${ }^{1}$ Doutora em Educação (UNISINOS, 2015), docente na Universidade Federal do Rio Grande/FURG e pesquisadora do Nós do Sul: Laboratório de Estudos e Pesquisas Sobre Identidades, Currículos e Culturas. Com o olhar na América Latina, se ocupa com os seguintes temas de pesquisa: Feminismo, Educação Popular e processos de exclusão social.

${ }^{2}$ Doutor em Educação (UFF, 2011), docente na Universidade Federal do Rio Grande/FURG e pesquisador do Nós do Sul: Laboratório de Estudos e Pesquisas Sobre Identidades, Currículos e Culturas. Os seus temas de interesse e pesquisa são: 1. currículos e culturas; 2. masculinidade(s) e 3. população lésbica, gay, bissexual, travesti e transexual e 4. estudos decoloniais e subalternos. Editor da Revista Momento: diálogos em educação.
} 
nos a analisar os modos como as dinâmicas androcêntricas desestabilizam e deslegitimam a presença da mulher, com agenda pró-progressista ${ }^{3}$, no cenário político brasileiro. Para tanto, balizamos nossa análise na emergência eleitoral da candidatura Dilma Rousseff, em 2010, para a Presidência da República, e panoramicamente traremos elementos de seus mandatos até o golpe jurídico-parlamentar-midiático, em 2016.

Assim sendo, dividimos o texto em três momentos: no primeiro, debatemos os referenciais de condução da análise, para, no segundo momento, debater a campanha presidencial de 2010 e, posteriormente, refletir acerca dos mandatos da Presidenta Dilma Rousseff. Dados os espaços em que atuamos e interagimos, aprendemos ao longo da vida sobre como mulheres e homens devem se comportar. Este cenário nos auxilia a afirmar que as redes de significados em torno do sexo estão capilarizadas, e elas criam e legitimam performatividades, as quais garantem a inteligibilidade do corpo sexual nas relações sociais e culturais. Os entendimentos sobre os sexos, muitas vezes binários, são resultantes da complexa maquinaria (escola, família, religião, políticas públicas, ciência, entre outras) que nos educaram cotidianamente e que acionamos na construção do ideário de masculino e feminino.

Se entendemos o sexo como um feito social, marcado pelos sentidos construídos pela e com a cultura, e, com isso, a ideia do corpo como constructo politico e cultural, sua noção e natureza se fazem duvidosas. Judith Butler ${ }^{4}$ (2003), ao dialogar com Simone de Beauvoir (2009), nos ensina que o gênero é uma forma de existir do próprio corpo. O corpo é uma situação carregada de possibilidades culturais, recebidas e reinterpretadas ao mesmo tempo. Então, com este diálogo, pensamos que tanto gênero quanto o sexo são questões culturais. Se o corpo "natural" é uma ficção, assim como a natureza do sexo, Butler, a partir deste diálogo, nos diz que sexo foi gênero.

Desde o início, o sexo é normativo, é um "ideal regulatório", como conceituou Michel Foucault (1988). O sexo não só funciona como norma, como também é parte de uma prática reguladora que produz os corpos que governa. É o discurso, cuja força se manifesta como

\footnotetext{
${ }^{3}$ Partimos da ideia de que a presença da mulher na política brasileira está diretamente associada à forma como ela opera com os valores androcêntricos, sexistas, classistas, racistas, capaticista e LGBTfóbico. Em outras palavras, sua condição feminina a impõe desvantagem quando sua agenda política opera no enfrentamento às hierarquias culturais, sexuais e econômicas, bem como aos valores anteriormente ditos.

${ }^{4}$ Utilizaremos o nome e sobrenome do/a autor/ar na primeira citação. Nas citações seguintes, os/as autores/as passam então a ser mencionados apenas com o último sobrenome. Seguimos essa orientação como uma forma inclusiva de perceber a produção científica. Paulo Freire faz referência à importância do lugar da linguagem inclusiva após ser criticado por sua linguagem machista por feministas norte-americanas que leram sua principal obra - Pedagogia do Oprimido (1964). Freire admite seu machismo e retoma esta questão na Pedagogia da Esperança, publicada em 1992, passando, então, a utilizar uma linguagem inclusiva.
} 
uma espécie de poder produtivo, que atravessa a subjetividade e se materializa nos modos individuais de entendimento de si. O sexo é o poder de produzir os contornos, os limites e as diferenças dos corpos que controla. Ele é um ideal regulatório, cuja materialidade se impõe e se desenvolve mediante certas práticas sumárias. Em outras palavras, é uma construção ideal, que se perpetua obrigatoriamente através do tempo e dos espaços. Não é uma realidade simples ou uma condição estática de um corpo, é um processo mediante o qual as normas reguladoras materializam o sexo. E este, por sua vez, desenvolve a materialidade em virtude da reiteração forçada da norma dicotômica dos sexos.

Para entender a dicotomia entre os sexos, precisamos recorrer aos princípios que orientaram a formação dos Estados Nacionais. Mesmo que esse texto não se pretenda histórico, usaremos de seu expediente para construir a análise aqui pretendida. No momento em que a ciência, na modernidade, constrói sua autonomia frente ao domínio teológico, também era promovida a leitura do conceito de cidadania ${ }^{5}$ nas teorias filosóficas de Estado.

O dispositivo conceitual que melhor fundamentou a cidadania moderna foi a fraternidade. Ligado às ideias de liberdade e igualdade, o conceito forma o tripé que caracterizou o pensamento revolucionário na França do século XVIII. No entendimento sobre a fraternidade, o homem, enquanto animal político e com condições de cidadania, escolheu conscientemente viver em sociedade e estabeleceu uma relação de igualdade com seus semelhantes. O limite da virtude descrita pelo entendimento fraterno teve início quando se analisou o temperamento do Homem e da mulher.

O valor e a justiça entre os sexos não são iguais, porque suas naturezas são diferentes, dizia Jean-Jacques Rousseau (1997). Nesta lógica, o valor de um homem se demonstra pela autoridade e o da mulher por sua obediência. Isto porque, segundo Diana Maffías (2005), o entendimento da alma humana era composto de razão e emoção. Como toda diferença, no geral, resulta em hierarquia, uma das partes (racional) governava a outra parte (emoção).

Na modernidade, o sujeito de conhecimento se configura como sendo um ser balizado na razão e afastado emocionalmente do campo e do "objeto" de análise. Nesta lógica, a própria masculinidade se transforma em um estereótipo em que a emoção é ignorada e reiteradamente negada da verdade. Nesta perspectiva, se o racional é oposto ao emocional, e o primeiro seria uma virtude masculina, a emoção é essencialmente feminina.

\footnotetext{
5 Aqui não é de nosso interesse realizar um levantamento das configurações conceituais assumidas pelo conceito. Mas apresentar sobre um enfoque de gênero, alguns critérios que foram criados para exercitá-lo. Independente da corrente filosófica, ele é entendido como principio básico para acessar os direitos e ser reconhecido/a como sujeito político.
} 
Esta discussão nos permite observar a dicotomia sexual adotada por Rousseau (1995:

431) ao pensar o sujeito universal. Para o autor:

[...] Todas as faculdades comuns aos dois sexos não lhes são igualmente repartidas; mas encaradas em conjunto elas se compensam. [...] Cultivar nas mulheres as qualidades do homem, e negligenciar as que lhes são peculiares, é pois visivelmente trabalhar contra elas. [...] Acreditai-me, mãe judiciosa, não façais de vossa filha um homem de bem, como que para dar um desmentido à natureza; fazei dela uma mulher honesta e ficai certa de que ela valerá mais com isso, para ela e para nós. [...] Elas devem aprender muitas coisas, mas as que lhes convém saber. [...] A mulher e o homem são feitos um para outro, mas sua dependência natural não é igual: os homens dependem das mulheres por seus desejos; as mulheres dependem dos homens por seus desejos e suas necessidades; nós subsistiríamos mais sem elas do que elas sem nós.

As afirmações de Rousseau e as interpretações do sujeito universal se materializaram, em maior ou menor grau, nas concepções políticas e ideológicas de todo o Ocidente. Em seu ensaio intitulado The feminist standpoint revisited and other essays, Nancy Hartsock em 1988 desenvolve um marco teórico que denomina o "ponto de vista feminista". Ao observar o sistema patriarcal, a autora resgata a ideia de Karl Marx e defende que o sexismo ${ }^{6}$ que estrutura a divisão sexual do trabalho permite às mulheres a experiência insubstituível de desenvolver uma relação ontológica com o conhecimento: a autoridade epistemológica. Harstock (1998) defende que o conhecimento é essencialmente emancipatório e permite ver como o sexismo causa prejuízo e dirige as mulheres, balizado pela lógica androcêntrica de organização da existência social.

$\mathrm{O}$ androcentrismo não representa somente a centralidade e supremacia do homem em relação à mulher nem, por sua vez, a submissão da mulher ao homem, enquanto coletivo de sujeito. Ele se caracteriza por meio das inúmeras responsabilidades que, a todo instante, são assumidas pelo homem e levam-no a naturalizar o governo de si, da família e do público. $\mathrm{Na}$ leitura de Marcio Caetano (2016) e Amanda Castro (2017), existe uma aproximação que nos obriga a ver a misoginia, o androcentrismo, a heteronormatividade, o racismo e o classismo como conceitos que se entrecruzam na manutenção do patriarcado e das desigualdades culturais, sexuais, econômicas, etc.

Caetano (2016) afirma que a heteronormatividade se conecta diretamente com o androcentrismo e a misoginia; primeiramente, porque sustenta a ideia do governo masculino

\footnotetext{
${ }^{6}$ É importante lembrar que o sexismo se trata de uma posição, que pode ser perpetrada tanto por homens quanto por mulheres; portanto, ele está presente no interior das relações entre mulheres tanto quanto nas relações entre mulheres e homens. Inscrita numa cultura falocrática (centrada nos valores de supremacia androcêntrica, ou seja, do homem), o sexismo impregna o imaginário social e o prepara a um vasto conjunto de representações socialmente partilhadas, de opiniões e de tendência a práticas que desprezam, desqualificam, desautorizam e violentam as mulheres ou o feminino, tomadas como seres ou comportamentos de menor prestígio social.
} 
sobre o feminino, até mesmo sobre o que é produzido pelo e com o corpo da mulher; segundo, pois, ao exigir a tarefa de governo do homem e de governo da mulher, os obrigam a relações intrínsecas e reprodutivas do sistema em uma lógica binária patriarcal. Segundo Neuma Aguiar (2000: 01), "o patriarcado se pauta pela dominação do público sobre o privado". Sendo assim, historicamente, o que é produzido pelas mulheres no cotidiano privado é avaliado como de menor valor social, se comparado ao que é produzido pelos homens nos espaços públicos.

\section{CAMPANHA ELEITORAL DE 2010}

Ainda que Luiz Inácio Lula da Silva estivesse impossibilitado de concorrer no processo eleitoral de 2010, sua participação na campanha de Dilma Rousseff à Presidência do Brasil foi determinante. A popularidade do Presidente, alcançada com o equilíbrio econômico e político, - fruto de um governo centrado na democratização do direito ao consumo e no $\mathrm{PAC}^{7}$ - foi disputada até pelos setores adversários ao Partido dos Trabalhadores (PT). Conhecido por sua capacidade de realizar articulações políticas, o Presidente Lula contou ainda com um forte apelo emocional, formulado a partir da força que a figura da mulher carregava enquanto expressão do novo no cenário político. Apelando aos valores judaicocristãos da maternidade, Lula afirmava:

A Dilma é na verdade, a mãe, a avó e a tia do PAC. Aprendi que se a gente anuncia uma obra e não fica atrás dela o tempo inteiro, essa obra não acontece. A Dilma coordena um conselho gestor, que participa ela, o ministro da Fazenda, o do Planejamento, o do Transporte, das Cidades e da Integração. Por quê? Senão a gente anuncia o dinheiro e passa o mandato e o dinheiro não chega, não sai do Tesouro, muitas vezes porque os prefeitos não têm experiência e não cumprem as exigências $(\mathrm{G} 1,2008$ : s/p).

Outro dia, no Rio de Janeiro, eu disse que a Dilma era a mãe do PAC. E por que ela é a mãe do PAC? É porque o PAC só funciona porque esta mulher, certamente, toma mais conta do PAC do que tomou da filha dela (FOLHA DE SÃO PAULO, 2008: s/p).

Conforme podemos observar nos pronunciamentos do então Presidente Lula, a presença feminina em seus discursos foi assinalada pelos tradicionais marcadores que relacionavam as mulheres aos papéis "clássicos" de maternidade, cuidadora e provedora. Nestes atributos, a presença feminina no mundo público somente seria permitida quando ela

\footnotetext{
${ }^{7}$ O Programa de Aceleração do Crescimento - PAC, lançado em 28 de janeiro de 2007 pelo Presidente Luiz Inácio Lula da Silva caracterizou-se como sendo um conjunto de políticas econômicas que teve como objetivo central acelerar o crescimento econômico do Brasil. Sua centralidade estava no investimento em infraestrutura, em áreas como habitação, saneamento, energia e recursos hídricos, entre outras políticas de infraestrutura.
} 
está centrada na lógica doméstica. É devido ao conhecimento produzido pelos campos dos Estudos de Gênero e Feministas que podemos, atualmente, compreender como operam as complexas redes de produção históricas das assimetrias sexuais androcêntricas e como elas são usadas no interior das dinâmicas políticas eleitorais, sobretudo, por setores progressistas.

Marcela Lagarde (2011), ao analisar as assimetrias sexuais, sinaliza que isso ocorre, principalmente, pela naturalização das redes sociais e culturais que alocam as mulheres no interior das fronteiras da maternidade e do matrimônio, do âmbito doméstico, as quais se tornam como que o seu lugar por excelência. A autora acrescenta, ainda, que o sistema heterossexual é uma das molas mestras do capital, por isso, não é à toa que a candidata Dilma Rousseff teve constantemente sua identidade sexual posta em xeque. Entrevista coletiva de Dilma em Teresina, durante sua visita ao Estado do Piaú, em 13 de outubro, o jornalista Efrém Ribeiro, do jornal Meio Norte (2010), deixou a presidenciável Dilma Rousseff (PT) transtornada ao perguntar sobre sua identidade sexual, "A senhora é homossexual?", perguntou o jornalista. Ela que já sinalizava a forte pressão religiosa à sua candidatura, respondeu irritada: “Ah, meu querido, não vou responder a isso, eu tenho uma filha e sou avó, pelo amor de Deus". Esse tipo de discussão eu não vou ter aqui". Nas palavras de Heleieth Saffioti:

[...] Não basta, entretanto, conhecer a capacidade humana de transformar o reino natural. É preciso atentar para o processo inverso, que consiste em naturalizar processos socioculturais. Quando se afirma que é natural que a mulher se ocupe de espaço doméstico, deixando livre para o homem o espaço público, está-se, rigorosamente, naturalizando um resultado da história (SAFFIOTI, 1987: 11).

Em outras palavras, a inserção da mulher no mundo público, quando isso ocorre, precisa caminhar ao lado das obrigações históricas que lhe foram designadas. O discurso presidencial a respeito da Ministra da Casa Civil, Dilma Rousseff, somente se alterou em 2009. Oportunamente, ao lado de domínio doméstico, as qualidades profissionais da Ministra foram enaltecidas, a fim de elevá-la à candidatura pelo Partido dos Trabalhadores à Presidência da República. No dia 3 de abril de 2010, a Ministra da Casa Civil, Dilma Rousseff, que nunca havia disputado um cargo eletivo até então, deixou a equipe ministerial para se candidatar ao cargo de presidenta do país, com irrestrito apoio de Lula. Nove candidatos/as disputaram a eleição presidencial de 2010: Dilma Rousseff (PT), Plínio Sampaio (PSOL), José Serra (PSDB), José Maria Eymael (PSDC), Zé Maria (PSTU), Levy Fidelix (PRTB), Marina Silva (PV), Rui Costa Pimenta (PCO) e Ivan Martins Pinheiro (PCB). Não diferente das eleições ocorridas desde 1998, o pleito presidencial continuou polarizado entre o Partido dos Trabalhadores (PT) e o Partido da Social Democracia Brasileira (PSDB). 
Dilma Rousseff não foi a única mulher a se destacar no cenário eleitoral daquele ano: a ex-Ministra do Ambiente do Governo Lula, Marina Silva, ao romper com o PT, lançou-se candidata pelo Partido Verde e acabou por se configurar como uma das grandes revelações de 2010. Ela conquistou uma imensa fatia do eleitorado. De acordo com o TSE, cerca de 20 milhões de votos, provavelmente dos eleitores que estavam insatisfeitos com os discursos das principais candidaturas e, sobretudo, com as denúncias do Mensalão, envolvendo a gestão petista. Não diferente de outras eleições presidenciais, a imprensa brasileira assumiu posições. No jogo midiático, em vários momentos, os temas jornalísticos e as propagandas eleitorais se mesclavam. Contudo, algo se destacou no cenário eleitoral, era corrente a contrapropaganda que se construiu em torno da imagem negativa da candidata petista, atrelando a sua militância à $\mathrm{VPR}^{8}$, ao ateísmo e ao aborto.

Fotografia 1 - interrogatório de Dilma em 1970

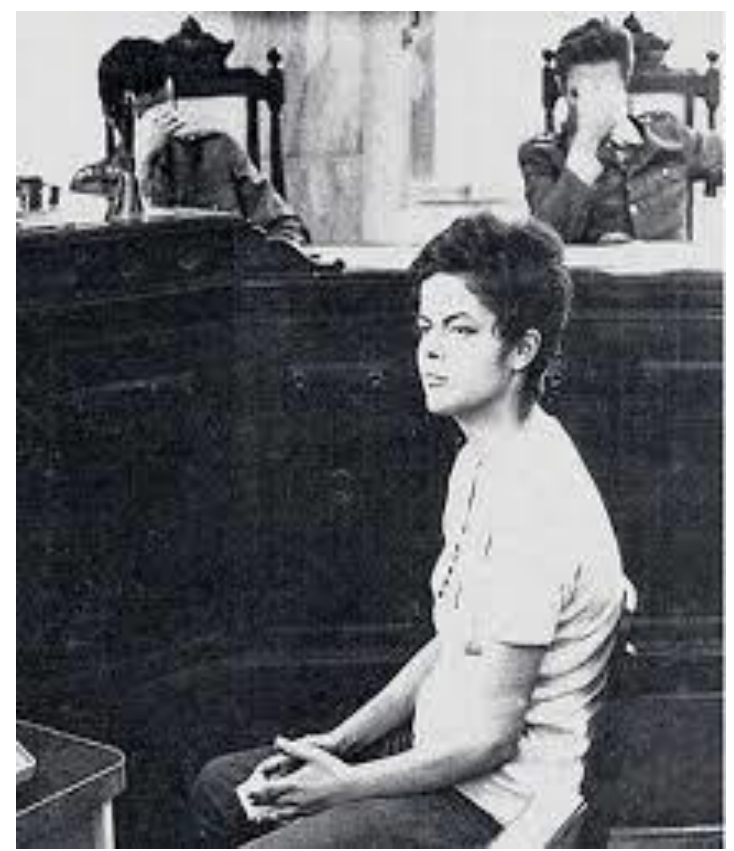

Fonte: http://revistaepoca.globo.com/Brasil/noticia/2011/12/foto-inedita-mostra-dilma-em-interrogatorio-em1970.html

Na clara tentativa de construir uma imagem que associasse a candidata às ameaças aos valores da família nuclear simples, da religião judaico-cristã e da pátria nacionalista, os

\footnotetext{
${ }^{8}$ No ensino médio, em 1964, ela conheceu o primeiro marido, Claudio Galeno, com quem se casou em 1967, ano em que entrou no curso de Ciências Econômicas da Universidade Federal de Minas Gerais (UFMG) e aderiu ao Comando de Libertação Nacional (Colina), organização que combatia a ditadura e que se fundiu com a Vanguarda Popular Revolucionária (VPR), formando a VAR-Palmares. A VAR-Palmares fez algumas ações armadas contra a ditadura, mas Dilma, que atuava em estratégia e planejamento, não participou de nenhuma delas. Nas campanhas eleitorais, essa passagem de sua vida era muito explorada.
} 
discursos conservadores aprofundavam a ligação da candidatura de Dilma Rousseff às agendas progressistas. De uma desestabilização econômica até a possível dissolução da fé cristã pelo fim da Igreja ou pela aprovação do aborto, foram algumas temáticas presentes na agenda eleitoral. Neste jogo midiático, foi inegável a força das redes virtuais, em especial os discursos realizados por meio do Twitter, Instagram e Facebook. Neles, os chamados fake news ${ }^{9}$, assombravam e veiculavam conteúdos virais. Segundo Marcelo Branco, coordenador de internet da campanha de Dilma Rousseff (PT):

[...] a grande novidade desta eleição, com milhões de eleitores "podendo se expressar" pelos canais virtuais. O excesso de "boatos" e de informações falsas sobre a candidata petista mancharam o processo democrático, sobretudo no $1^{\circ}$ turno. Não posso deixar de registrar um repúdio a esse tipo de atitude, porque isso não é campanha política. Isso é bandidagem (BBC - BRASIL, 2010: s/p).

A comunicação virtual ou telefônica usou de todos os expedientes possíveis para desqualificar o debate eleitoral, trazendo ao cenário público temáticas ultraconservadoras e convocando os eleitores e as eleitoras a se posicionarem por meio do voto. No twitter, facebook e Instagram, as candidaturas e partidos encontravam alternativas para divulgar suas posições sobre os/as adversários/as políticos/as, suas ideias sobre o desenvolvimento do país, agendas de campanhas e também criar uma aproximação com o eleitorado.

São 7 e meia da manhã da segunda-feira 18 em Salvador. Toca o telefone na casa do estudante H. A. Ele atende. Ouve uma voz de mulher, que diz: "Você é eleitor e vai votar na Dilma?" E desfia rapidamente as denúncias contra a ex-ministra da Casa Civil, Erenice Guerra. No dia seguinte, às 10 horas, na cidade-satélite de Taguatinga, no Distrito Federal, o telefone toca na casa da advogada Melissa Carvalho. Voz feminina novamente. "Você vai votar em Dilma? Então saiba que ela era favorável ao aborto e depois mudou de opinião. Não dá para confiar em um candidato assim", e coisas do gênero. Não adianta a pessoa tentar responder: tratase de uma gravação. Telefonemas similares têm ocorrido em todo o País. Os relatos se sucedem no Twitter. Em Minas Gerais, há casos distintos, onde a operadora pergunta se a pessoa que atende o aparelho votou em Marina Silva. Em caso positivo, inicia-se um discurso contra o voto no segundo turno em Dilma Rousseff. Quem paga por essas centrais de telemarketing anti-Dilma? Ninguém sabe. O PT pediu investigação à Polícia Federal sobre o caso, uma das muitas denúncias que têm brotado do jogo sujo praticado contra a candidata de Lula. O próprio presidente veio a público reclamar da campanha difamatória, dizendo nunca ter visto em sua vida eleição com tamanho baixo nível [...]. (MENEZES, 2010: s/p).

Os virais, mais tarde denunciados por Dilma no debate da TV Bandeirante, do dia 10 de outubro de 2010, como sendo enviados pela equipe de Índio da Costa - candidato a vice-

\footnotetext{
${ }^{9}$ Podemos considerar a expressão como um neologismo usado para se referir às notícias fabricadas que são veiculadas nas redes sociais virtuais, whatsapp, email e periódicos e, por ser tantas vezes reproduzidas, acabam por assumir uma ideia de veracidade. O fake New é escrito e publicado com a intenção de enganar e obter, no geral, benefícios financeiros e/ou políticos.
} 
presidente na chapa de José Serra, eram repassados de usuários/as a outros/as (DEBATE BAND, 2010) ${ }^{10}$. Os conteúdos e formas se apropriavam de três recursos principais que buscavam mobilizar o eleitorado: o humor, a denúncia e a desqualificação da autoridade da candidata. O cenário envolvendo a eleição assemelha-se ao dito por Jean-Jacques Courtine (1999: 19), "a constituição de um espaço do repetível toma a forma de uma retomada palavra por palavra, de discurso em discurso, de numerosas formulações" que visa a constituição de uma verdade verdadeira. $\mathrm{O}$ autor continua a prerrogativa de intercepção temporal ao postular a ideia da presença de rituais discursivos contínuos, que, em outras palavras, "produzem um corte temporal ligando o presente da enunciação ao passado - e também ao futuro discursivo, em uma anulação imaginária dos processos históricos” (COURTINE, 1999: 20).

Os conteúdos divulgados no processo eleitoral mesclavam temas que se centravam em torno do casamento gay e do aborto. Esta estratégia tinha a clara intenção de trazer ao cenário eleitoral posicionamentos anteriores, que poderiam questionar a fé cristã de Dilma Rousseff. A prática era investigar para denunciar e, com isso, confirmar as teorias de conspiração.

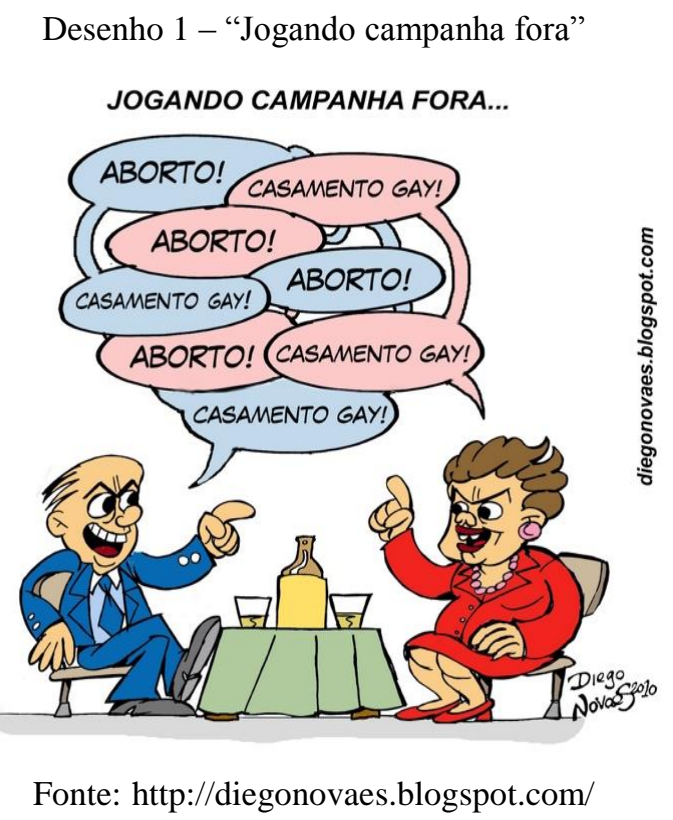

Ao falar em política de desqualificação, não significava dizer que todas as notícias que circulavam pela Internet, com denúncias fossem falsas, mas, sem dúvida, criavam o clima social capaz de mobilizar o eleitorado. Visto que, diferente dos grandes temas, a exemplo da macroeconomia e geração de emprego, as pautas morais atravessavam os eleitores

\footnotetext{
10 Mantivemos esta remissão, a despeito da Rede Bandeirantes ter bloqueado o vídeo do youtube face a direitos autorais.
} 
imediatamente. A outra categoria presente nos virais era marcada pelo uso do humor com finalidade de expor a candidatura a situações ridículas, a exemplo da que segue:

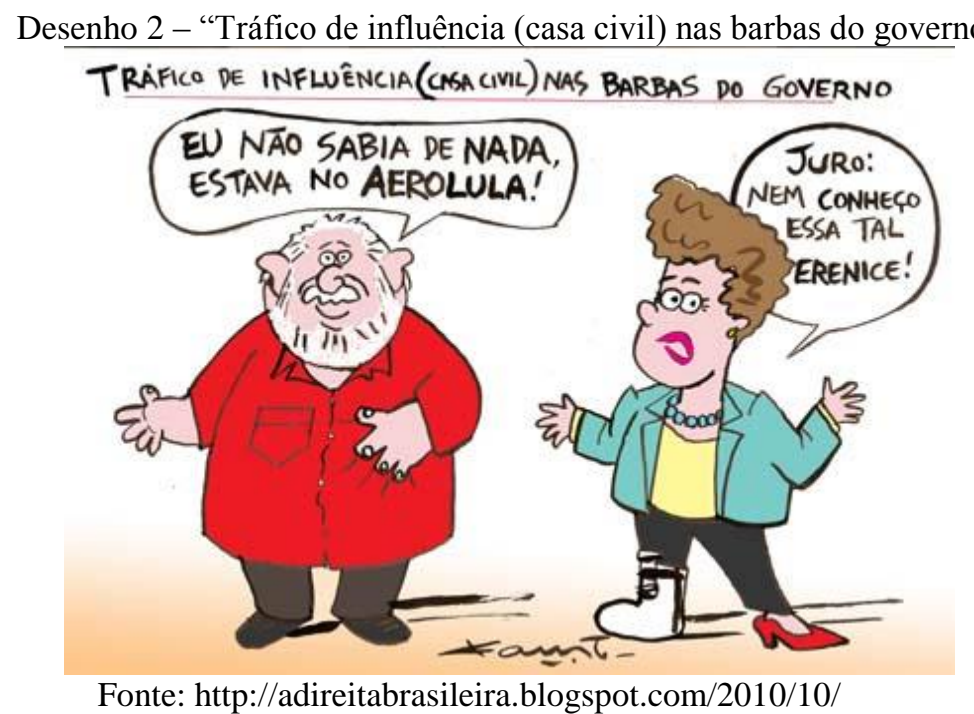

O esdrúxulo prevaleceu, e as candidaturas foram estereotipadas, e os candidatos, transformados em temas centrais de caricaturas.

O humor provocativo de ataque, alicerçado numa 'retórica agressiva', pela qual a persuasão se alicerça no medo do ridículo, apresenta sempre um valor dialógico, intertextual (no sentido de remeter para discursos anteriores ou ainda por proferir) e uma marca divergente (relativa ao facto de serem considerados insultuosos) (CAMILO, 2008: 02).

A estratégia agressiva de ridicularização não foi exclusivamente produzida pelas campanhas, vários conteúdos foram "caseiramente" disseminados. A comunicação virtual viral, no geral, é caracterizada por sua capacidade de isentar seus vínculos. Um dos episódios mais emblemáticos do processo eleitoral, após as sucessivas denúncias de ateísmo e apoio ao aborto, foi a visita de Dilma Rousseff à Basílica de Nossa Senhora da Aparecida, em 11 de outubro de 2010

A candidata à Presidência Dilma Rousseff (PT) assistiu nesta segunda-feira, 11, à missa no santuário Nossa Senhora Aparecida, que visitou pela primeira vez, embora - conforme disse em entrevista - seja devota de Nossa Senhora, especialmente Nossa Senhora Aparecida. "Queria estar aqui em Aparecida por causa de um problema recente de minha vida, que prefiro não comentar", disse Dilma, referindo-se ao câncer que enfrentou recentemente. A candidata chegou a Aparecida de helicóptero, entrou na Basílica às $8 \mathrm{~h} 47$ e ficou na primeira fileira, em uma área reservada diante do altar, sentada entre o chefe de gabinete pessoal do presidente, Gilberto Carvalho e o recém-eleito deputado federal Gabriel Chalita (PSB), além de prefeitos e deputados da região. Na coletiva após a missa, Dilma comentou o debate de domingo, 10, à noite, estranhando ter sido chamada de agressiva por alguns jornais, dizendo que o debate foi de alto nível e que ela aproveitou o encontro para cobrar do candidato José Serra (PSDB) a campanha da 
qual se sente vítima. Dilma considera normal esse embate da forma que foi porque são apenas dois candidatos num debate de duas horas. A candidata deixou Aparecida logo depois com destino a Brasília onde participará de um comício em Ceilândia e gravará programas para o horário eleitoral (MAYRINK, José Maria, Estado de S. Paulo, 11 de Outubro de 2010).

Em plena campanha para o Planalto, a pré-candidata pelo Partido dos Trabalhadores, Dilma Rousseff, impulsionada pela agenda conservadora reformulou radicalmente, várias vezes, o seu discurso sobre a fé. Antes era público que Dilma afirmava não ter religião específica e, em vários aspectos, acreditava-se em seu ateísmo. A transformação foi ainda maior se for levado em consideração o período que precede sua pré-candidatura. A petista, sempre quando interpelada, costumava contar sua trajetória de estudo em instituições católicas, e que, inclusive, havia sido batizada e crismada. Contudo, mesmo reiterando este discurso, sua entrevista às jornalistas Carla Gullo e Maria Laura Neves (s/a) da Revista Marie Claire era constantemente mencionada nos debates. Na ocasião da entrevista, a então ministra da Casa Civil afirmou que não praticava a religião.

\section{Fotografia 2 - Capa da revista Veja}
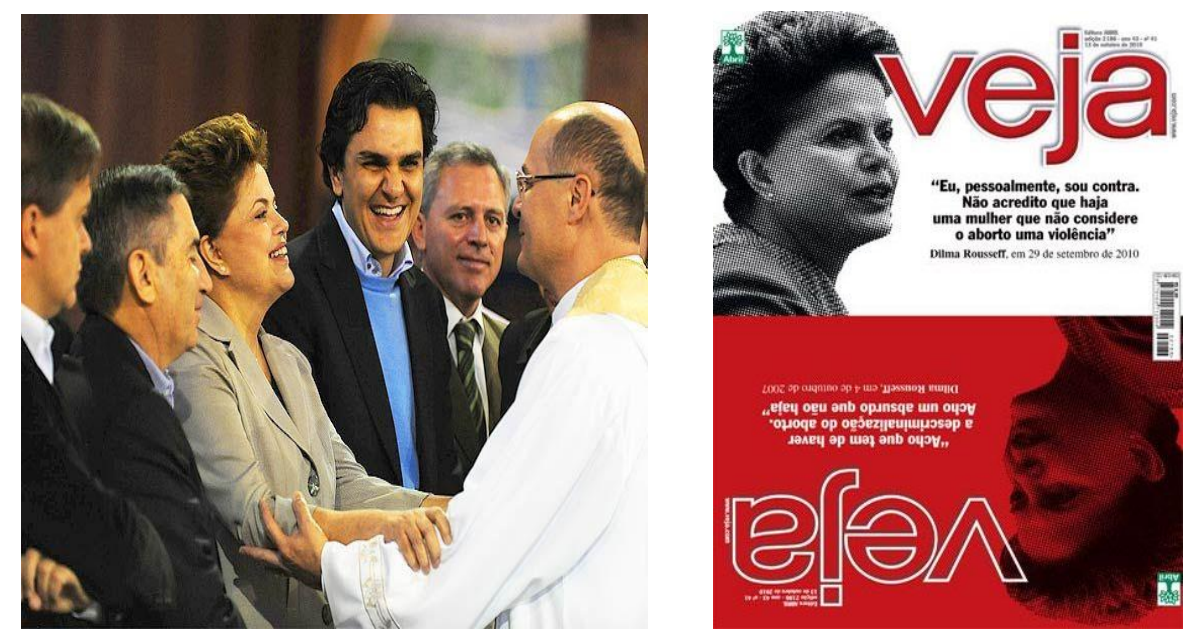

Fonte: https://somosandando.com.br

O candidato do PSDB, José Serra, orientou o debate eleitoral para temas genéricos, e com profundo teor moralista, destacando tal teor quando interpelado: "Eu quero ser um presidente com postura, equilíbrio e que defenda os valores da família brasileira: os valores cristãos, a democracia, o respeito à vida e ao meio- ambiente”. Frente a esse cenário, Dilma se viu obrigada a reestruturar suas táticas eleitorais ao ter que responder às acusações que, periodicamente, lhe eram imputadas, lembrando-nos aquilo que Gomes (2004: 223) destaca: 
Enquanto condição ético-pragmática, a ética da disputa argumentativa pública inclui a exigência da verdade: exige-se de quem argumenta uma espécie de vontade de verdade, ou a vontade de alcançar um acordo argumentativo sobre a verdade por meio do debate argumentativo.

A utilização na retórica de argumentos que carecem de comprovação pelos/as oradores/as no embate político, segundo Chan Perelman e Olbrechts-Tyteca (1996), não provocam vazios no discurso, e, a depender da forma como o sujeito o posiciona, ganham um status de verdade. Quando pensamos em discursos políticos proferidos nas disputas eleitorais, o uso de valores morais e temas que produzem paixões ancoram boa parte dos argumentos produzidos no contexto. O uso de argumentos "falsos" é, de certa forma, admissível. O que está em xeque é o caráter do/a candidato/a, e na disputa eleitoral é admissível o uso de "armas letais" contra os adversários. Diante dos sujeitos que compuseram a disputa eleitoral de 2010, é pertinente lembrar Van Dick (2008: 84) quando afirma que: "crucial no exercício do poder, então, é o controle da formação das cognições sociais por meio da manipulação sutil do conhecimento e das crenças, a pré-formulação das crenças ou a censura das contraideologias".

Em 2010, houve uma proliferação de discursos moralistas de cunho religioso, que sobressaíram aos temas referentes às questões administrativas. "Não há sociedade onde não existam narrativas maiores que se contam, se repetem e se fazem variar" (FOUCAULT, 1996: 22). Os temas foram debatidos como um "ultraje" aos valores hegemônicos da família brasileira, excitando medos difusos. Dentro dessa lógica, Dilma lançou a "Carta ao povo brasileiro". 
Fotografia 3 - "Carta ao povo brasileiro"

Olá meus amigos, irmãs e irmãos brasileiros.

Quero me dirigir a vocês, com o carinho e o respeito que merecem todos aqueles que junto conosco, lutam, trabalham e sonham com um Brasil cada vez melhor, mais justo e mais perto da premissa do evangelho que é "desejar ao próximo aquilo que queremos para nós mesmos".

Aliàs, o sonho e o compromisso do evangelho são em muitos aspectos, o sonho e o compromisso de um governante sensivel e comprometido com o povo e com os menos favorecidos. Exemplo visto e vivenciado pelo nosso querido presidente Lula e seu governo, do qual me orgulho de ter feito parte e dado uma parcela significativa de contribuiçăo.

Najo temos como negar que os programas "Bolsa Familia", "Minha Casa Minha Vida" e tantos outros que assistem as populaçōes mais carentes traduzem esse compromisso na prática. É uma forma de resgatar os valores da vida, da cidadania e da dignidade humana, valores universais que trazem em si a semente do evangelho valores estes que nosso governo tem se esmerado a perseguir e que nos impulsionam a buscar mais um mandato.

Como cidadãos comprometidos năo podemos aceitar passivamente as injustiças sociais, a violência, indices de agressōes contra mulheres e mães indefesas. Isto nos leva ao compromisso de fazer da familia o foco principal de nosso governo. Respeitar o elo sagrad

tenham dignidade, respeito e valor será o norte de nosso próximo governo.

Compreendemos o quanto as igrejas, todas sem distinçăo de denominações cristăs, são importantes e necessárias neste projeto de apoio e resgate da familia e da sociedade.

das açōes do Governo. Elas săo responsáveis por uma grande e invisivel rede social, isto é louvável e traz em si a necessidade da măo amiga do Estado, dando sua contrapartida, tanto em termos de facilitaçằo do acesso às politicas públicas, como em termos de organizaçă de um diálogo constante com o governo. Compromisso este que assumo em meu eventual governo. Quero construir esse diálogo com as instituiç̃es que tem estecedores do sofrimento humano. Entendo seu valor, sua luta e seu trabalho impulsionado pela missão do evangetho.

Lembro também minha expectativa de que cabe ao Congresso Nacional a funçăo básica de encontrar o ponto de equilibrio nas posiçōes que envolvam valores éticos e fundamentais, muitas vezes contraditórios,

das favelas brasileiras e tantas outras distorçōes sociais, que a meu ver tem o dedo imperfeito do homem e năo o designio de um Deus perfeito.

Sabemos que em situaçōes de pobreza, desigualdade social e violência, os que mais sofrem são as criancas e os jovens. Sáo eles as maiores vitimas de sociedade insensivel $e$ injusta, onde poucos sempre tem as melhores oportunidades.

A familia sempre foi e será o baluarte de uma sociedade saudável. Quanto mais estruturada é a familia, menos caos social teremos. E no desajuste familiar que vemos nascer 0 abandono infantil gerando os chamados meninos de rua. É na violência doméstica que temos a semente dos adolescentes infratores marcados pela dor vivenciada caos familiar que temos os altos

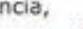
como aborto, formaço familiar, unioes estaveis outros temas relevantes, tanto para as minorias como para toda sociedade brasileira.

Assim sendo, meus amigos, quero terminar reafirmando minha posição de que, qualquer açăo só é eficaz com determinação e fé e que é a esperança que motiva nossa caminhada.

Rogo a Deus que me dê forças para cumprir minha missão, para que juntos possamos transformar nossa paixão em açăo em favor deste novo Brasil que está nascendo.

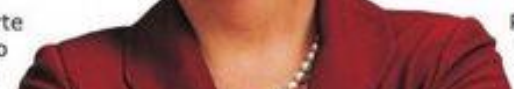

eço sua oraçăo e seu voto para que eu tenha a oportunidade de continuar o projeto deste Brasil que está finalmente dando certo, năo apenas p a r a privilegiados, mas para todos.

Um abraço de sua amiga e companheira,

Dilma Rousseff.

\section{Carta aberta ao povo de Deus}

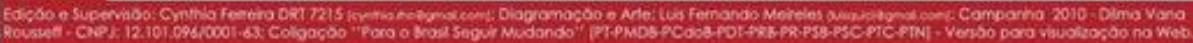

Fonte: https://pt.slideshare.net/marinetemerss/carta-aberta-ao-povo-de-deus-dilma

O PNDH-34 ${ }^{11}$, a declaração pública de Dom Luiz Gonzaga Bergonzini, Bispo de Guarulhos, orientando os fiéis a não votarem no PT e o vídeo do Pastor Paschoal Piragine Júnior, da Primeira Igreja Batista de Curitiba, fazendo orientações semelhantes (PRIMEIRA IGREJA BATISTA DE CURITIBA, 2010), provocaram intensa repercussão no quadro eleitoral. A relevância dos dogmas religiosos no processo eleitoral converteu-se em critério

11 Terceira versão do Programa Nacional de Direitos Humanos (Decreto 7,037/2009, atualizado pelo Decreto 7.177 de 12 de maio de 2010. 
decisório das eleições, sobretudo, no segundo turno. Silvia Cervelini, Malu Giani e Patrícia Pavanelli argumentam que (2010: 38):

A despeito do peso que outros fatores (como as denúncias do caso Berenice, de quebra de sigilo, das declarações de Lula sobre imprensa, do fato de que a candidata Dilma não tinha ainda uma imagem consolidada junto ao eleitorado e já, em sua primeira eleição, disputava a Presidência da República, entre outros) possam ter exercido na eleição presidencial de 2010, acreditamos que a polêmica em torno do tema aborto foi decisiva para o prolongamento e desfecho da disputa no segundo turno.

"A Carta Aberta ao Povo de Deus" foi uma resposta ao eleitorado judaico-cristão quanto às crenças e aos valores da candidata petista. O compromisso de Dilma Rousseff com a agenda religiosa não se limitou ao processo eleitoral. Cleyton Feitosa (2017: 298) argumenta que:

Já na campanha de 2010, Dilma publicou uma carta direcionada aos cristãos se comprometendo a não avançar em pautas como o direito ao aborto e às reivindicações LGBT como a criminalização da homofobia (neste caso, ela afirma sancionar caso o Senado aprovasse, revogando conteúdos que ferissem a liberdade religiosa).

A campanha foi conduzida pelo binômio: mentira/verdade; mal/bem; cristão/ateu. Nesta esteira, facilmente é possível observar a forma com que os/as candidatos/as se apropriaram dessas categorias em seus discursos. A própria campanha de José Serra (PSDB) tinha como refrão de seu jingle a expressão "Serra é do bem”. Pensando na lógica dualista que ancora a cidadania patriarcal, que destacamos na primeira parte do texto, o jingle de Serra nos leva ao entendimento que os/as demais candidato/as não seriam bons.

Com intensa estratégia ofensiva, a candidatura de José Serra questionava, em todos os seus programas televisivos, a idoneidade de sua oponente, Dilma Rousseff. O candidato tucano reiterava o discurso de que sua trajetória política era 'verdadeira' e o legitimava ao cargo de presidente do Brasil. Em outras palavras, parecia induzir à mensagem de que a candidatura de Dilma foi artificialmente projetada pelo Presidente Lula e que seria ele a governar o país. Foucault (1996) nos ajuda a entender a estratégia de Serra quando diz que:

A verdade a mais elevada já não residia mais no que era o discurso, ou no que ele fazia, mas residia no que ele dizia: chegou um dia que a verdade se deslocou para o ato ritualizado, eficaz e justo, de enunciação, para o próprio enunciado: para seu sentido, sua forma, seu objeto, sua relação a sua referência (FOUCAULT, 1996: $15)$.

Talvez, desde a redemocratização, as Igrejas (Evangélica, Neopentecostal e Católica) não tenham se posicionado tanto no processo eleitoral brasileiro. Inúmeros setores se manifestaram contra a candidatura de Dilma Rousseff (PT), alegando que a candidata seria 
favorável ao aborto ou às pautas contrárias aos interesses da agenda judaico-cristã. Essas manifestações foram intensamente viralizadas pelas redes sociais por líderes religiosos, a exemplo da mensagem de Dom Aldo Di Cillo Pagotto, Arcebispo Metropolitano da Paraíba (PAGOTTO, 2010). Courtine (1999, p. 21) nos ajuda a entender a estratégia ao dizer que:

Uma repetição que é ao mesmo tempo ausente e presente na série de formulações: ausente porque ela funciona aí sob o modo do desconhecimento, e presente em seu efeito, uma repetição na ordem de uma memória lacunar ou com falhas (COURTINE, 1999: 21).

Por todos os fatores citados, indiscutivelmente, os discursos moralistas que orientaram a campanha de 2010 influenciaram no retrocesso da democracia brasileira. As questões morais de cunho conservador afloraram ou foram impostas pela agenda de governabilidade nos projetos de governo, e também se constatou a prevalência da retração das agendas progressistas em relação a setores historicamente alijados da agenda política cidadã, a exemplo da população de lésbicas, gays, bissexuais, travestis e transexuais.

Com 63 anos de idade, tomou posse a primeira mulher presidenta do Brasil, com $46,91 \%$ dos votos válidos. A mineira Dilma Rousseff, diferente dos demais presidentes, chegou ao Palácio do Planalto em companhia de sua filha, Paula Rousseff. Mesmo que a forte chuva no dia da posse tenha impedido a realização de todo o trajeto em carro aberto, cerca de 30 mil pessoas acompanharam a cerimônia.

Em seu discurso de posse, Dilma Rousseff adotou um tom conciliador, fez promessas de continuidade das políticas do governo Lula e o mencionou algumas vezes, "A maior homenagem que posso prestar a ele é ampliar e avançar as conquistas do seu governo. Reconhecer, acreditar e investir na força do povo foi a maior lição que o Presidente Lula deixou para todos nós", afirmou a Presidente empossada.

Pela decisão soberana do povo, hoje será a primeira vez que a faixa presidencial cingirá o ombro de uma mulher. Sinto uma imensa honra por essa escolha do povo brasileiro e sei do significado histórico desta decisão. Sei, também, como é aparente a suavidade da seda verde-amarela da faixa presidencial, pois ela traz consigo uma enorme responsabilidade perante a nação. Para assumi-la, tenho comigo a força e o exemplo da mulher brasileira. Abro meu coração para receber, neste momento, uma centelha da sua imensa energia. E sei que meu mandato deve incluir a tradução mais generosa desta ousadia do voto popular que, após levar à presidência um homem do povo, um trabalhador, decide convocar uma mulher para dirigir os destinos do país. Venho para abrir portas para que muitas outras mulheres também possam, no futuro, ser presidentas; e para que - no dia de hoje - todas as mulheres brasileiras sintam o orgulho e a alegria de ser mulher. Não venho para enaltecer a minha biografia; mas para glorificar a vida de cada mulher brasileira. Meu compromisso supremo - eu reitero - é honrar as mulheres, proteger os mais frágeis e governar para todos! (ROUSSEFF, 2010: s/p). 
De fato, naquele momento se iniciava uma nova era para as mulheres na política brasileira. Naquele ano, além de Dilma Rousseff, 45 deputadas federais foram eleitas, além de oito senadoras e duas governadoras. Um número baixo, se levado em consideração o total de parlamentares (513 deputados federais, 54 senadores e 27 governadores), mas um número alto, pensando no contexto sócio-político do Brasil: um país patriarcal, em que a cultura machista é amplamente enraizada e onde a mulher só conquistou o direito ao voto em 1932. Ao longo do seu mandato, Dilma Rousseff deu poder a um time feminino em pelo menos dez ministérios - e ainda nomeou Graça Foster para a presidência da Petrobrás. No dia 21 de setembro de 2011, Dilma Rousseff foi a primeira mulher a discursar na abertura da Assembleia Geral da ONU. No início de seu discurso, ela pontua:

Pela primeira vez, na história das Nações Unidas, uma voz feminina inaugura o Debate Geral... É com humildade pessoal, mas com justificado orgulho de mulher, que vivo este momento histórico. Divido esta emoção com mais da metade dos seres humanos deste Planeta, que, como eu, nasceram mulher [...] Na língua portuguesa, palavras como vida, alma e esperança pertencem ao gênero feminino, e são também femininas duas outras palavras muito especiais para mim: coragem e sinceridade. Pois é com coragem e sinceridade que quero lhes falar no dia de hoje. (FOLHA DE SÃO PAULO, 2011: s/p).

O discurso proferido em Nova York entrou para história da ONU e foi singular ouvir o lugar político em que Dilma se colocou como mulher, e é importante para compreender a desigualdade histórica entre os sexos sustentada pela lógica patriarcal (CASTRO, 2017).

Com forte emoção, lembramos do dia da posse do seu primeiro mandato como Presidenta do Brasil, em $1^{\circ}$ de janeiro de 2011. Recordamos de uma das jornalistas ter comentado que a Presidenta fez a solicitação para que toda a guarda policial que acompanhasse o carro oficial na posse fosse feita por mulheres. Ali, nós feministas e homens pró-feministas já percebíamos o tom do governo de Dilma Rousseff.

A autora Svetlana Aleksiévitch, na década de 1980, escreveu o dramático livro A guerra não tem rosto de mulher, a partir da reflexão feita por Aleksiévitch em relação à guerra. Fazendo uma analogia à política brasileira, ousamos aqui dizer que a política brasileira não tem rosto de mulher, e, quando tem, para tal mulher se manter no poder precisa assumir uma agenda conservadora. No Planalto Central, o homem engravatado, branco, judaicocristão, velho e proprietário, muito semelhante ao sujeito universal de Rousseau, dá o tom da política brasileira e por meio dela articula os modos e rumos androcêntricos da sociedade brasileira. E a pergunta que muitas/os de nós fazíamos era: como Dilma Rousseff iria manejar o machismo e a influente sociedade patriarcal após eleição em 2010? Como sinalizado Ilse Gomes Silva (2016: 143), 
O governo Dilma não se afastou do padrão de intervenção do período de Lula. Entretanto o agravamento da crise mundial limitou a margem de manobra e as possibilidades de manter o equilíbrio instável entre os interesses em disputa das diversas frações da burguesia e os setores populares que constituíam a base social do governo. Nesse cenário de tensão quem mais se destaca pela ofensiva contra os governos do PT é o setor de direita e de extrema direita que encontra no PMDB e no PSDB, a base parlamentar para empreender uma campanha pelo impeachment da presidente Dilma com ares de legalidade e legitimidade constitucional. Soma-se a esta empreitada o apoio de setores do aparelho de Estado como o judiciário, inclusive o ministério público, a polícia federal e a forte mobilização do aparelho ideológico, com destaque para a grande mídia e as igrejas neopentecostais.

Segundo o documento Radiografia do Congresso Nacional: legislatura 2015/2019 do DIAP - Departamento Intersindical de Assessoria Parlamentar, as bancadas eleitas ao Congresso Nacional em 2010 não foram favoráveis à aprovação de temáticas relacionadas aos direitos humanos e sociais. De acordo com o documento, o Congresso foi composto de: empresários, 221 deputados; Ruralistas, 109; Evangélicos, 75; Sindicatos, 51 e Segurança, 22. Em entrevista à Carta Capital, André dos Santos, do DIAP, informou que a bancada BBB (boi, bala e bíblia) (MARTINS, 2015) possuía cerca de 40\% dos votos da Câmara e tinha atuado de modo articulado e unificado nas votações de projetos da agenda conservadora. Mesmo com a eleição de Dilma, a composição do Congresso Nacional indicava que os setores mais conservadores assumiram a centralidade política no Brasil.

As manifestações de 2013, com o apoio da grande mídia, conseguiram neutralizar a visibilidade das políticas sociais que garantiram os governos petistas e substituiu pelo discurso do combate à corrupção. Sem dúvida, as constantes denúncias, iniciadas ainda no Governo Lula, se fortaleceram e, em 2015, legitimaram as manifestações contra a Dilma Rousseff. Usando verde e amarelo e cantando o hino nacional, as manifestações eram motivadas pelo sentimento de "basta de corrupção".

A agenda conservadora no Congresso Nacional é extensa e diversificada. No campo dos direitos humanos temos o Estatuto da Família (projeto 6583/13) que restringe o núcleo familiar à união entre homem, mulher e filhos; a revogação do Estatuto do Desarmamento; o Projeto 171/93 de redução da maioridade penal de 18 para 16 anos para crimes graves. No campo dos direitos dos trabalhadores temos, por exemplo, o projeto que muda nas regras do seguro desemprego e do reajuste do salário mínimo; o Projeto de 4330/2004 conhecido como o projeto da terceirização que aumenta a precarização do trabalho. Tem ainda o projeto que garante a independência do Banco Central; a aprovação do novo Código Florestal (2012) e a PEC 215, que retira do Executivo a prerrogativa de demarcar terras indígenas (SILVA, 2016: 147). 
Outra marca conservadora do primeiro mandato da Presidenta Dilma Rousseff, referese ao kit anti-homofobia ${ }^{12}$, planejado pelo Ministério da Educação. Impulsionada pela pressão da bancada evangélica, a Presidenta vetou a campanha de enfrentamento à homofobia nas escolas e, graças a sua desastrosa assessoria, foi infeliz ao declarar que seu governo não faria campanha de opção sexual (PASSARINHO, 2011). O fato é que no plenário da Câmara, o então deputado carioca, Anthony Garotinho (PR), chegou a reivindicar a demissão de Fernando Haddad do Ministério da Educação. Garotinho, que era vice-presidente da Frente Parlamentar Evangélica, por meio da imprensa chegou a afirmar que a bancada evangélica, composta, segundo ele, por 74 deputados, não votaria nenhum projeto enquanto o governo não recolhesse os materiais da campanha anti-homofobia.

Mesmo com toda a adversidade, Dilma terminou seu primeiro mandato com apoio popular e enfrentou uma segunda campanha política em 2014 pela reeleição, vencendo nas urnas com 51,64\% dos votos válidos - o que corresponde a 54.501 .118 votos. O candidato tucano, também nascido em Minas Gerais, Aécio Neves, ao ter conhecimento da derrota, se pronunciou avisando que seria oposição ao governo sem dar trégua (KRAKOVICS, 2014, s/p), e foi exatamente isso o que fez. Dilma tomou posse para seu segundo mandato como Presidenta da República em 1 de janeiro de 2015, com uma forte oposição. Meses após sua posse, Aécio Neves e José Serra, ambos do PSDB, afirmaram com convicção: "Dilma não terminará seu mandato" (EL PAÍS, 2015).

A partir dessa conjuntura, o que tivemos no Brasil foi a total confusão e manipulação dos fatos, principalmente pela grande mídia, sistema judiciário, partidos políticos e empresários. O país foi levado, assim, a assistir a um circo político que culminou com o golpe contra a Presidenta Dilma Rousseff, no dia 31 de agosto de 2016. Por 61 votos a favor e 20 contrários, a Presidenta, democraticamente eleita, foi afastada e condenada sob a acusação de ter cometido crimes de responsabilidade fiscal, as chamadas "pedaladas fiscais".

O que mais nos impressionou foi, sem dúvida, a força que Dilma teve durante todo seu “julgamento" no Congresso Nacional, respondendo às perguntas e acusações contra o seu

12 O kit integrava as ações do Projeto "Escola sem Homofobia", desenvolvido entre 2008 e 2011, e que tinha como objetivo enfrentar a homofobia (atualmente convencionou-se usar LGBTfobia considerando que a violência e discriminação atinge de diferente forma lésbicas, gays, bissexuais, travestis e transexuais.) no ambiente escolar. Fruto da parceria entre o Ministério da Educação com as organizações Pathfinder do Brasil, Ecos e Reprolatina, com o apoio da ABGLT, as ações do Projeto buscaram a realização dos seguintes produtos: 1) Pesquisa em 11 (onze) capitais brasileiras sobre a temática; 2) Realização de 5 (cinco) Seminários Regionais sobre a temática; e 3) Desenvolvimento de kits de materiais didáticos para serem distribuídos em escolas de Ensino Médio. Contudo, toda a iniciativa foi interrompida em 2011, quando o "kit anti-homofobia" foi suspenso pelo MEC, com a justificativa de que o material audiovisual seria inadequado para uso em sala de aula, com o público previsto. 
mandato. Durante todo o seu processo de afastamento e o período posterior, percebíamos como o fato de ser mulher fazia com que ela fosse "duplamente" atacada. Se, de um lado projetavam-se os discursos de incapacidade administrativa e ausência de habilidade política; de outro, a Presidenta, semelhante ao que ocorreu na campanha eleitoral de 2010, via sua figura de mulher ser aviltada publicamente, a exemplo da imagem abaixo, que, mesmo sendo profundamente desrespeitosa, reproduzimos para ilustrar a dimensão misógina dos discursos de oposição:

Fotografia 4 - Adesivo usado em protestos contra o aumento do valor dos combustíveis
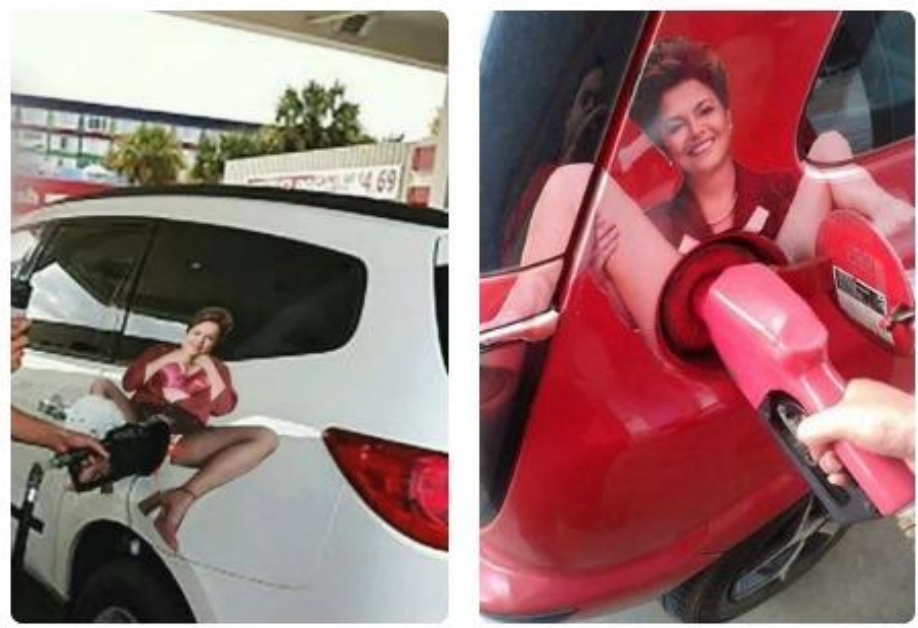

Fonte: http://www.vermelho.org.br/noticia/266588-8

A imagem acima se refere a um adesivo comercializado durante certo tempo no site "Mercado Livre" por R\$ 34,00, e que foi usado quando houve "protestos" contra o aumento dos combustíveis. Logo, seu impeachment foi um golpe para ela, para a democracia e para as mulheres. Em maio de 2016, a estudante Thais Viyuela (2016) escreve um forte artigo intitulado A política não veste saia. Ela está certa: se Dilma fosse homem ou se a política usasse saia, talvez a história tivesse sido bem diferente.

\section{CONSIDERAÇÕES FINAIS}

Quem se debruça sobre estudos da educação popular sabe que a esperança é uma categoria central na condução de nossa militância. Falar em esperança na atual conjuntura política, social e moral brasileira é quase uma "insanidade" ou um desafio. Desde o golpe, em 2016, retrocedemos nas políticas públicas em educação, direitos humanos, políticas para minorias/maiorias, saúde, direitos trabalhistas, direitos reprodutivos, segurança, distribuição 
de renda, previdência social, entre outros setores que aqui não conseguimos listar, porque o tempo é curto e as perdas são grandes.

Não tenhamos dúvidas que os retrocessos têm atingido mais duramente as populações combatidas pela sociedade patriarcal, racista, classista e sexista. As mulheres, populações negras, pobres e de lésbicas, gays, bissexuais, travestis, transexuais e intersexuais estão no "olho do furação" e no centro dos ataques.

Dentro desta lógica, para que a esperança, enquanto categoria histórica que nos ensinou Paulo Freire (2001: 63), faça sentido, é preciso seguir a luta: "não é, porém a esperança um cruzar de braços e esperar. Movo-me na esperança enquanto luto e se luto com esperança, espero". Logo, a esperança também provoca raiva, luta e movimento, sobretudo quando estamos diante das condições que nos negam o "ser mais".

$\mathrm{Na}$ atual conjuntura é lutar ou lutar. E os professores e as professoras têm uma função importante nesse momento histórico. Cabe também à educação cuidar da esperança para que ela não se desvie e não se perca caminhando para a desesperança e desespero. Essa também é uma tarefa docente! Por esse motivo os cursos sobre o golpe midiático-jurídico-parlamentar contra a presidenta Dilma ministrados em 2018 em várias Universidades Públicas Brasileiras foram de grande força, pois sinalizaram nosso compromisso em conhecer a história e buscar transformá-la. Terminamos este ensaio com esperança, mesmo que não a vejamos nitidamente..., pois é por causa da esperança que lutamos!

\section{REFERÊNCIAS}

AGUIAR, Neuma. 2000. Patriarcado, sociedade e patrimonialismo. Sociedade \& Estado. vol.15 no.2 Brasília Jun/Dez.

\section{BBC - BRASIL. 2010. Assessor de Dilma na web diz que mentiras mancharam a} campanha. Disponível em: http://www.bbc.com/portuguese/noticias/2010/10/101021_internet_sub2_fp. Acessado em março de 2018.

BUTLER, Judith. 2003. Variaciones sobre sexo y género. In: LAMAS, Marta. El género: la construcción cultural de la diferencia sexual. Cidade do México: Unam/Pueg, p. 303326.

CAETANO, Marcio. 2016. Performatividades reguladas: narrativas biográficas, heteronormatividade e educação. Curitiba: Appris.

CAMILO, Eduardo. 2008. Vendendo às gargalhadas. Apontamentos sobre o estatuto do humor na comunicação publicitária. In: CD das Atas das III Jornadas de Publicidade e Comunicação: Porto, Universidade Fernando Pessoa. 
CASTRO, Amanda Motta. 2017. Feminismo, violência e formação docente!. In: Katemari Diogo da Rosa, Marcio Caetano, Paulo Castro. (Org.). Gênero e sexualidade: intersecções necessárias à produção de conhecimentos.Campina Grande: FURG Realize.

CASTRO, Amanda Motta. 2017. Unos piqueticos: ¡A pesar de ellos es preciso luchar sin temer!. In: Nivia Ivette Núñez de la Paz, Romi Márcia Bencke. (Org.). Presidenta Dilma: en sororidad mujeres rescatan la historia. São Leopoldo: Karywa.

CERVELLINI, Silvia; GIANI, Malu; PAVANELLI, Patrícia. 2011. Economia, Religião e Voto: a Questão do Aborto na Eleição Presidencial de 2010. IV Congresso LatinoAmericano da World Association for Public Opinion Research, Belo Horizonte: UFMG.

COURTINE, Jean-Jacques. 1999. O chapéu de Clémentis. In: INDURSKY, Freda; FERREIRA, Maria Cristina. (org.) Os múltiplos territórios da Análise do Discurso. Porto Alegre: Sagra Luzzatto, p. 15-22.

DEBATE BAND, 2010. Debate entre DILMA X SERRA. Publicado em 10 de outubro de 2010. Disponível em https://www.youtube.com/watch?v=-yS6aw8L160 Acessado em abril de 2018.

DEPARTAMENTO INTERSINDICAL DE ASSESSORIA PARLAMENTAR. 2014. Radiografia do Novo Congresso: Legislatura 2015-2019 / Brasília, DF: DIAP. 164 p.: il. ; color. (Estudos Políticos do DIAP). Disponível em: http://www.diap.org.br/index.php?option=com_jdownloads\&Itemid=217\&view=finis h \&cid=2883\&catid=41. Acessado em junho de 2018.

EL PAÍS. 2015. Serra assegura que Dilma não acabará o mandato. É crível ? Disponível em : $\quad$ https://brasil.elpais.com/brasil/2015/01/30/opinion/1422647442_830138.html Acessado em maio de 2018.

FREIRE, Paulo. 2001. Pedagogia do oprimido. 45. ed. São Paulo: Paz e Terra.

FREIRE, Paulo. 2003. Pedagogia da esperança. Um reencontro com a pedagogia do oprimido. São Paulo: Paz e Terra.

FEITOSA, Cleyton. 2017. Mapeando demandas por participação política da população LGBT no Brasil. BAGOAS n. 17, p. 282-317.

FOLHA DE SÃO PAULO. 2008. Presidente Lula afirma que Dilma é mãe, avó e tia do PACH. http://www1.folha.uol.com.br/folha/brasil/ult96u393239.shtml. Acessado em abril de 2018.

FOLHA DE SÃO PAULO. 2011. Discurso disponível em <http://feeds.folha.uol.com.br/fsp/mundo/ft2209201105.htm> Acessado em maio de 2018.

FOUCAULT, Michel. A ordem do discurso. São Paulo: Edições Loyola, 1996. 
G1. 2008. "Dilma é mãe, avó e tia do PAC" Diz Lula. Disponível em: http://g1.globo.com/Noticias/Politica/0,,MUL413988-5601,00-

DILMA+E+MAE+AVO+E+TIA+DO+PAC+DIZ+LULA.html. Acessado em abril de 2018 .

GOMES, Wilson. 2004. Transformações da política na era da comunicação de massa. São Paulo: Paulus.

GULLO, Carla.; NEVES Maria L. A mulher do presidente. Revista Marie Claire. Disponível em http://revistamarieclaire.globo.com/Marieclaire/0,6993,EML16978261739,00.html. Acessado em junho de 2018.

HARTSOCK, Nancy. 1998. The feminist standpoint: developing the ground for a specifically feminist historical materialism. In: The feminist standpoint revisited and other essays. Colorado: Westview Press, p. 105-132.

KRAKOVICS, Maria L. 2014. De volta ao Senado, Aécio Neves promete 'oposição sem trégua'. Disponível em: https://oglobo.globo.com/brasil/de-volta-ao-senado-aecioneves-promete-oposicao-sem-tregua-14454633\#ixzz5PhIMgIFG Acessado em abril de 2018.

LAGARDE, Marcela. 2011. Los cautiverios de las mujeres: madres, monjas, putas, presas y locas. Ciudad de Mexico: UNAM.

MAFFÍA, Diana. 2005. El contrato moral. In: CARRIÓ, Elisa; MAFFÍA, Diana. Búsquedas de sentido para una nueva política. Buenos Aires: Paidós.

MARTINS, Rodrigo. 2015. A bancada BBB domina o Congresso https://www.cartacapital.com.br/revista/844/bbb-no-congresso-1092.html Acessado em maio de 2018.

MAYRINK, José Maria. 2010. Dilma visita santuário Nossa Senhora Aparecida. Disponível em: http://politica.estadao.com.br/noticias/geral,dilma-visita-santuarionossa-senhora-aparecida-no-interior-de-sao-paulo,623428. Acesso em maio de 2018.

MEIO NORTE. 2010. Dilma você é homossexual? Eu não vou responder. Disponível em: https://www.youtube.com/watch?v=n8xcN5cLQeM. Acessado em abril de 2018.

MENEZES, Cynara. 2010. Papéis e Papelões. Disponível em: https://www.cartacapital.com.br/politica/papeis-e-papeloes. Acesso em março de 2018 .

PAGOTTO, Dom Aldo. 2010. Posicionamento de Dom Aldo Pagotto sobre "a cultura do aborto". Publicado em 10 de outubro de 2010. Disponível em: https://www.youtube.com/watch?annotation_id=annotation_25368\&feature=iv\&src_v $\underline{\mathrm{id}=-\mathrm{yS} 6 \mathrm{aw} 8 \mathrm{~L} 160 \& \mathrm{v}=\mathrm{j} 2 \mathrm{q} 2 \mathrm{DI} 9 \mathrm{RsUo}}$. Acesso em abril de 2018.

PASSARINHO, Nathalia (2011). Governo não fará 'propaganda de opção sexual' diz Dilma sobre o kit. Matéria disponibilizada pelo jornal G1. Disponível em: 
http://g1.globo.com/educacao/noticia/2011/05/governo-nao-fara-propaganda-deopcao-sexual-diz-dilma-sobre-kit.html Acessado em abril de 2018.

PERELMAN, Chan.; OLBRECHTS-TYTECA, Lucie. 1996. Tratado da argumentação: a nova retórica. São Paulo: Martins Fontes.

PRIMEIRA IGREJA BATISTA DE CURITIBA. 2010. Posicionamento do Pr. Paschoal Piragine Jr sobre as eleições 2010. Publicado em 31 de Agosto de 2010. Disponível em: http://www.youtube.com/verify_age?next_url=/watch\%3Fv\%3DILwU5GhY9MI Acessado em abril de 2018.

PROGRAMA NACIONAL DE DIREITOS HUMANOS (Decreto 7,037/2009, atualizado pelo Decreto 7.177 de 12 de maio de 2010. Disponível em http://www.planalto.gov.br/ccivil_03/_ato2007-2010/2009/decreto/d7037.htm Acessado em maio de 2018.

REVISTA ÉPOCA. ANO. Foto inédita mostra Dilma em interrogatório em 1970. Disponível em http://revistaepoca.globo.com/Brasil/noticia/2011/12/foto-inedita-mostra-dilma-eminterrogatorio-em-1970.html Acessado em maio de 2018.

ROUSSEAU, Jean-Jacques. 1995. Emilio, ou da educação. Rio de Janeiro: Bertrand Brasil.

ROUSSEFF, Dilma. 2010. O Discurso pronunciado por Dilma Rousseff na cerimônia de posse. Disponível em <http://www.vermelho.org.br/noticia.php?id_noticia=144643 Acessado em maio de 2018.

SAFFIOTI, Heleieth. 1987. O poder do macho. São Paulo: Moderna.

SILVA, Ilse Gomes. 2016. A agenda conservadora assume o centro da cena política no Brasil. Lutas Sociais, São Paulo, vol.20 n.36, jan./jun, p.140-150.

VAN DIJK, Teun. 2008. Discurso e poder. São Paulo: Contexto.

VIYUELA, Thais. 2016. A política não veste saia. Disponível: https://www.huffpostbrasil.com/thais-viyuela/a-politica-nao-vestesaia_a_21696197/. Acessado em abril de 2018. 